\title{
Research on the load spectrum distribution and structure optimization of locomotive traction seats
}

\author{
W. Wang, M. Wang \& Z. Liu \\ Laboratory for Structural Strength Testing, \\ Beijing Jiaotong University, China
}

\begin{abstract}
As a result of long-time service, cracks started to emerge in traction seats of the $6 \mathrm{~K}$ locomotive. There is an urgent need for more reliable traction seat structures. The stress-time history of key points of traction seats was measured under $6 \mathrm{~K}$ locomotive operation condition. By methods of mean stress amendment and load identification, the load spectra for six traction seats were compiled. The statistic inference and the fitting test were processed on the load spectra, and the Weibull distribution function and the maximum load were deduced in order to have a more comprehensive understanding of the load distribution. With the help of ANSYS code, the optimization structures of traction seats were designed and the dynamic stress test was carried out. Combined with the S-N curve and Miner Law, the equivalent stress amplitudes of key points relative to service life were calculated. The results show that all of the equivalent stress amplitudes are less than the fatigue limit and the optimization structures meet with the operation requirement.
\end{abstract}

Keywords: load spectrum, equivalent stress amplitude, Weibull distribution, traction seat.

\section{Introduction}

The traction mechanism, transmitting the locomotive traction force, is one of the most important parts, ensuring the safety of the locomotive. As a result of long service under heavy loads, fatigue cracks emerge in traction seats of the $6 \mathrm{~K}$ locomotive. The quantity and size of cracks are increasing seriously, which has caused a security risk to the locomotive in service [1]. 
The "Z"-style traction rod is the typical type of $6 \mathrm{~K}$ locomotive. Six traction seats are welded to the wagon underframe and six traction rods are connected to three bogies, respectively. Statistics revealed that about $76 \%$ of cracks initiated from the welds between the cover plate of the traction seats and underframe beam [2]. Figure 1 shows the traction system and the connection between the traction seat and the underframe structure.

Based on the data processing of the stress-time history signal of the traction seats, the load spectra are compiled for each traction seat. Using the MATLAB tool, statistical inference and adaptive testing are processed to study the distribution characters of the load spectrum parent, and the maximum load is deduced by the probability method. Finally, the optimal structures are defined in terms of ANSYS code, as well as load spectra, and the equivalent stress amplitudes of key points of optimal structures were calculated.

\section{Testing and compilation of the traction seat load spectrum}

\subsection{Test condition}

The test line, about $288 \mathrm{~km}$, is the operation line for the $6 \mathrm{~K}$ electric locomotive. The track includes numerous curves, turnouts and an 11 13\% slope stretch of about $30 \mathrm{~km}$. The load of the test locomotive is 4,500 tons, which is the same as the maximum traction tonnage. Data acquisition is continuous in order to ensure the integrity of test data.

\subsection{Load identification}

Traction seat load is the tension and compression load from the traction rod. The load $F_{x}$ can be identified by strain gauges along the axle [3-5], or

$$
F_{x}=\frac{\pi}{4} \cdot D^{2} \cdot \sigma
$$

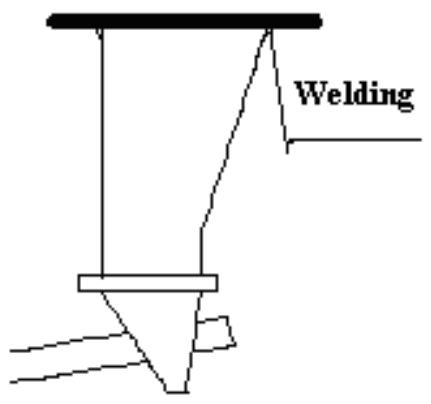

Figure 1: $\quad$ Traction system of the $6 \mathrm{~K}$ locomotive. 
where $D$ is the section diameter of the traction rod and $\sigma$ is the stress value obtained by the axial strain gauges.

\subsection{Load spectrum compilation method}

In order to get more accurate stress distribution, the spectrum compilation should take the stress average and amplitude as a binary random variable [6], which can be obtained by the rain flow counting process of the measured dynamic stresstime history and then be grouped by eqn. (2).

$$
\left\{\begin{array}{l}
D_{m}=\frac{\sigma_{m \text { max }}-\sigma_{m \text { min }}}{N_{m}} \\
D_{a}=\frac{\sigma_{a \text { max }}-\sigma_{a \text { min }}}{N_{a}}
\end{array}\right.
$$

where $D_{m}$ and $D_{a}$ are the group interval of stress amplitude and mean stress, respectively, $\sigma_{\text {mmax }}$ and $\sigma_{\text {m min }}$ are the maximum and minimum of mean stress, respectively, $\sigma_{a \max }$ and $\sigma_{a \min }$ are the maximum and minimum of the stress amplitude respectively and $N_{m}$ and $N_{a}$ are the total number of mean stress and amplitude series ,respectively, which here takes 8 .

In order to facilitate the optimization design of the structure, eqn. (3) is used to change the two-dimensional stress spectrum into a one-dimensional spectrum.

$$
\sigma_{-1 a i}=\frac{\sigma_{a} \sigma_{b}}{\sigma_{b}-\sigma_{m}}
$$

where $\sigma_{a}, \sigma_{m}$ are the stress amplitude and mean stress, $\sigma_{b}$ is the tensile strength of the material and $\sigma_{-1 a i}$ is the equivalent stress amplitude of each series for symmetric cycle.

\subsection{Test results of the stress spectrum and the load spectrum}

Table 1 shows the equivalent one-dimensional stress spectrum of the left $1 \#$ traction rod. According to eqn. (1), the stress data in Table 1 can be transformed into the load spectra, namely the traction seat load spectra, also shown in Table 1.

\section{Statistical inference of the load distribution characteristics}

In order to fully understand the parent distribution of the load spectrum of the traction seat, statistical analysis of the load spectra is performed. Weibull distribution is assumed according to the approximate shape of load amplitudefrequency histogram and then hypothesis testing is carried out to determine the mathematical model. 
Table 1: $\quad$ Stress spectrum and load spectrum.

\begin{tabular}{|c|c|c|c|}
\hline $\begin{array}{c}\text { Stress amplitude } \\
(\mathrm{MPa})\end{array}$ & Frequency & $\begin{array}{c}\text { Cumulative } \\
\text { frequency }\end{array}$ & $\begin{array}{c}\text { Load amplitude } \\
(\mathrm{KN})\end{array}$ \\
\hline 7.4 & 4217 & 8189 & 20.88 \\
\hline 12.1 & 2975 & 3972 & 34.15 \\
\hline 16.9 & 758 & 997 & 47.70 \\
\hline 21.7 & 174 & 239 & 61.41 \\
\hline 26.5 & 47 & 65 & 74.81 \\
\hline 31.0 & 11 & 18 & 87.68 \\
\hline 35.5 & 4 & 7 & 100.41 \\
\hline 40.5 & 3 & 3 & 114.36 \\
\hline
\end{tabular}

\subsection{Weibull function}

The probability density function of the three-parameter Weibull function can be expressed by eqn. (4).

$$
F(x)=\left\{\begin{array}{c}
\frac{b}{X_{a}-X_{0}}\left(\frac{X-X_{0}}{X_{a}-X_{0}}\right)^{b-1} \cdot \exp \left[-\left(\frac{X-X_{0}}{X_{a}-X_{0}}\right)^{b}\right] \quad \begin{array}{c}
X \geq X_{0} \\
0
\end{array} \quad X<X_{0}
\end{array}\right.
$$

where $X_{0}$ is location parameter, $b$ is shape parameter and $b>0, X_{a}$ is scale parameter and $X_{a}>0$;

The expectation of Weibull function is

$$
E(x)=\int_{0}^{\infty} x f(x) d x=X_{0}+\left(X_{a}-X_{0}\right) \cdot \tau\left(1+\frac{1}{b}\right)
$$

The deviation of Weibull function is

$$
\operatorname{Var}(x)=\int_{0}^{\infty}(x-\mu)^{2} f(x) d x=\left(X_{a}-X_{0}\right) \cdot\left[\tau\left(1+\frac{2}{b}\right)-\tau^{2}\left(1+\frac{1}{b}\right)\right]
$$

where $\tau(\cdot)$ is the Gamma function.

\subsection{Distribution function deduction of load}

Chi-square minimization method, namely, $\chi^{2}$ minimization method $[7,8]$ is used and parameter estimation of Weibull distribution for the load spectra is performed with the help of MATLAB tool.

The mean value and deviation of the load test subsample can be obtained based on the load amplitudes and frequencies, which can be supposed to be parameters of Weibull function as the subsample is in large quantity. In order to determine three parameters of Weibull function, another equation should be found except eqn. (5) and eqn. (6). Here taking $K$.pearson value as an objective 
function, $\chi^{2}$ minimization method is used to determine the optimal value of shape parameter $b$. Table 2 shows the fitting data and adaptive testing results of the relevant parameters of Weibull function.

The data in Table 2 show that the correlation $|R|$ value is greater than "the minimum value of correlation coefficient" in the $R$ test and in the $\chi^{2}$ test, $K$.pearson statistic values are less than the critical value, which verify that it is acceptable to suppose that the load statistical parent meets Weibull distribution.

\subsection{Inference of the maximum load}

The load spectra may not include the maximum service load due to the test limit. The probability calculation is a typical method to get the maximum load [9]. Table 3 shows the maximum load of each traction seat deduced from statistical inference. It can be found that the maximum amplification factor is 1.206 and the minimum is 1.083 compared with test data.

\section{Optimization of traction seats and fatigue life prediction}

\subsection{Optimization design of traction seats}

Taking the left 1 \# seat for example, the optimal structure is provided based on the maximum load. Fig. 2 shows the FEA results of both the improvement seat

Table 2: Parameter fitting and adaptive testing results of the Weibull function for the load spectra.

\begin{tabular}{|c|c|c|c|c|c|}
\hline \multirow{2}{*}{$\begin{array}{l}\text { Traction } \\
\text { seats }\end{array}$} & \multicolumn{3}{|c|}{ Parameters } & \multirow{2}{*}{$\begin{array}{l}\text { K.pearson } \\
\text { Statistics }\end{array}$} & \multirow{2}{*}{$\begin{array}{c}\text { Correlation } \\
\qquad|R|\end{array}$} \\
\hline & $b$ & $X_{0}$ & $X a$ & & \\
\hline Right 1\# & 0.7099 & 15.8788 & 19.317 & 4.44 & 0.99942 \\
\hline Right 2\# & 0.5573 & 17.0824 & 18.6873 & 5.47 & 0.99837 \\
\hline Right 3\# & 0.9487 & 12.6846 & 19.8244 & 6.11 & 0.97169 \\
\hline Left $1 \#$ & 0.9295 & 14.6116 & 23.4233 & 5.70 & 0.99054 \\
\hline Left 2\# & 0.8331 & 14.1651 & 19.9945 & 4.29 & 0.96381 \\
\hline Left 3\# & 0.5963 & 16.2452 & 18.244 & 3.11 & 0.99964 \\
\hline
\end{tabular}

Table 3: $\quad$ The maximum loads of each traction seat (Unit: KN).

\begin{tabular}{|c|c|c|c|c|c|c|}
\hline Traction seats & $\begin{array}{l}\text { Right } \\
1 \#\end{array}$ & $\begin{array}{l}\text { Right } \\
2 \#\end{array}$ & $\begin{array}{l}\text { Right } \\
3 \#\end{array}$ & $\begin{array}{l}\text { Left } \\
1 \#\end{array}$ & $\begin{array}{l}\text { Left } \\
2 \#\end{array}$ & $\begin{array}{c}\text { Left } \\
3 \#\end{array}$ \\
\hline Statistical inference & $3^{112.6}$ & $9^{104.4}$ & $1^{103.7}$ & $8^{132.8}$ & $5^{116.5}$ & $31^{105 .}$ \\
\hline Test Load & 93.36 & 95.51 & 88.33 & $6^{114.3}$ & 98.59 & $7^{97.2}$ \\
\hline $\begin{array}{l}\text { Amplification factor } \\
\lambda\end{array}$ & 1.206 & 1.099 & 1.174 & 1.162 & 1.182 & $3^{1.08}$ \\
\hline
\end{tabular}




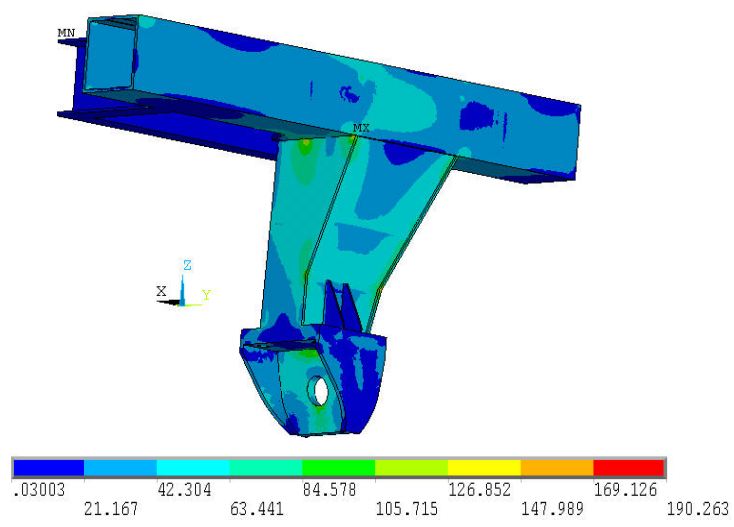

(a) Original seat

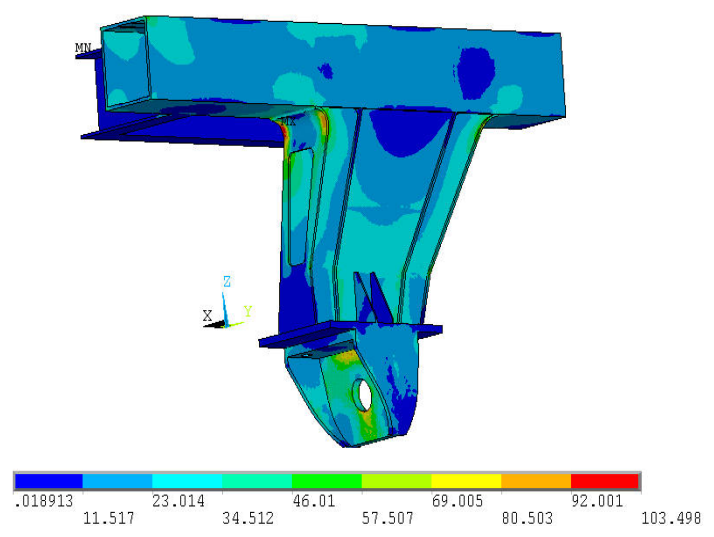

(b) Optimized seat

Figure 2: $\quad$ FEA analysis of the original and optimal design of traction seats.

and the original one. The comparison shows that the maximum stress of the weld connecting traction seat and the wagon underframe decreases from $190.3 \mathrm{MPa}$ to $63.1 \mathrm{MPa}$, and the maximum stress of the improved structure moves to the transition arc of reinforcement cover plate and the value is $103.5 \mathrm{MPa}$.

\subsection{Fatigue life prediction of the optimal traction seat}

In order to predict the fatigue life of the optimal traction seats, the dynamic stress test was carried out under the same operation condition and the equivalent stress amplitude was obtained according to the reference [8].Table 4 lists the equivalent stress amplitude results of the left 1 \# traction seat key points (location shown in fig.3), in which the extension life of $1,600,000 \mathrm{~km}, 2,000,000 \mathrm{~km}$ and $3,000,000 \mathrm{~km}$ corresponds to 8 years, 10 years and 15 years in service respectively. It can be seen that the equivalent stress amplitudes of measured 
points are all less than the admissible fatigue stress of $70 \mathrm{MPa}$, which means the optimized structure can be used safely in further $8 \sim 15$ years.

\section{Conclusion}

(1) The dynamic stress-time history of key points of traction seats was collected while the locomotive was in service and the load spectra were compiled respectively for the six traction seats based on the load identification method.

(2) The statistical inference and adaptive testing were processed to learn the distribution characters of the load spectrum parent. The results show that the load spectra of the traction seats meet Weibull function. The maximum load is deduced by the probability method as well.

(3) By modelling and performing analysis in ANSYS code, the optimal traction seat structures were defined. The online dynamic stress test and the fatigue life prediction were carried out. The results show that the fatigue life of traction seats can prolong to 8-10 years after the structure optimization.

Table 4: $\quad$ Equivalent stress amplitudes of left 1\# traction seat.

\begin{tabular}{|c|c|c|c|}
\hline Service life & $\begin{array}{c}1,600,000 \\
\mathrm{~km}\end{array}$ & $\begin{array}{c}2,000,000 \\
\mathrm{~km}\end{array}$ & $\begin{array}{c}3,000,000 \\
\mathrm{~km}\end{array}$ \\
\hline $\begin{array}{c}\text { Connection weld between cover plate and } \\
\text { underframe (non traction rod side, inner side) }\end{array}$ & 34.2 & 36.4 & 40.9 \\
\hline $\begin{array}{c}\text { Connection weld between cover plate and } \\
\text { underframe (non traction rod side, outside) }\end{array}$ & 27.7 & 29.6 & 33.2 \\
\hline Transition arc of the cover plate( inner side) & 36.0 & 38.4 & 43.1 \\
\hline Transition arc of the cover plate( outside) & 26.0 & 27.7 & 31.1 \\
\hline
\end{tabular}

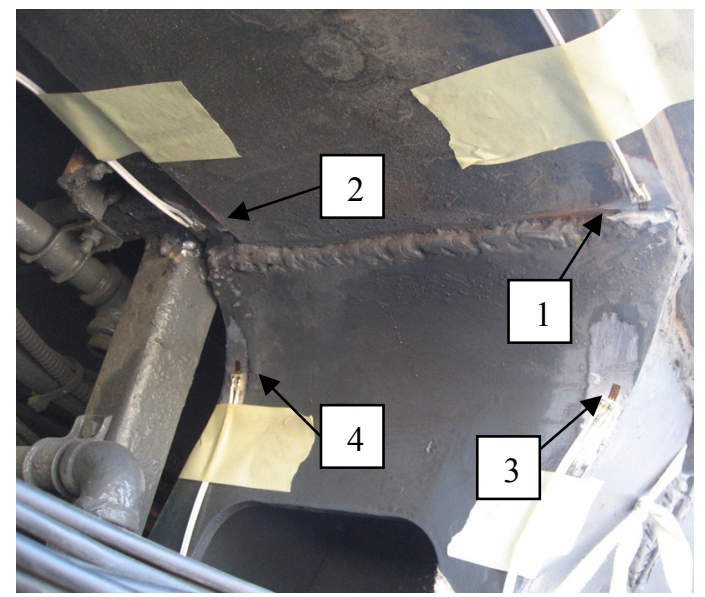

Figure 3: Location of the key points for measurement. 


\section{Acknowledgements}

The work is supported by "the Fundamental Research Funds for the Central Universities" and "Beijing Nova Program".

\section{References}

[1] Huang, Z. \& Zhang, H., Traction device's summarization of 3B0 locomotive, Diesel Locomotives, 40(11), pp.24-26, 2004.

[2] Yuan, J., 6K electric locomotive profile. Electric Locomotives and Mass Transit Vehicles, 11(1), pp. 37-41, 1988.

[3] Wang, F., Study on Fatigue Life and Reliability of Fatigue Life of Turn 8Gtype Device Cross-braced Bogies, Northern Jiaotong University, Master Thesis: Beijing, 2003.

[4] Liu, H., Mechanics of Materials (4th Edition), Higher Education Press: Beijing, pp40-45, 2004.

[5] Shi, C., Research of Load Identification and Distribution of SW-200 Bogie Frame, Northern Jiaotong University, Master Thesis: Beijing, 2006.

[6] Xiong, J. \& Gao, Z., Rain Flow - Back method and two-dimensional fatigue load distribution of hypothesis testing, Aviation Journal, 17(3), pp.297-301, 1996.

[7] Xu, Q., Software Development of Stress Spectrum Processing and Spectrum Analysis System on Locomotive Bogie, Northern Jiaotong University, Master Thesis: Beijing, 1999.

[8] Lv, P. \& Liu, Z., Research on statistical inference methods of stress spectrum of bogie, Journal of Northern Jiaotong University, 22(1), pp.44-50, 1998.

[9] Stephens, R.I., Fuchs, H., Stephens, R.R. \& Fatemi, A, Metal Fatigue in Engineering (2nd Edition), John Wiley and Sons: Hoboken, pp55-70, 2000. 